\title{
REFLEXÕES JURÍDICAS SOBRE CUSTOS AMBIENTAIS NO INCREMENTO DA EXPLORAÇÃO DOS HIDROCARBONETOS NÃO CONVENCIONAIS
}

Danielle Mendes Thame Denny

Advogada, Mestre e Doutoranda em Direito Ambiental Internacional pela Universidade Católica de Santos, professora na Fundação Armando Álvares Penteado e na Universidade Paulista.

\section{Maria Luiza Machado Granziera}

Advogada, Mestre e Doutora em Direito Público pela Universidade de São PauIo, Professora do Programa de Mestrado em Direito Ambiental da Universidade Católica de Santos, autora de diversos livros entre eles o Direito Ambiental, publicado pela Ed. Atlas.

\section{Resumo}

O barateamento da produção energética a partir do denominado gás de folhelho ${ }^{1}$, popularmente denominado gás de xisto, está crescendo exponencialmente nos Estados Unidos e Canadá, derrubando o preço do velho carbono, e tornando-se mais vantajoso em termos econômicos e assim dificultando ainda mais a competitividade das fontes renováveis de energia. Os impactos disso, além de serem de ordem comercial, são também de altíssima relevância para o meio ambiente, haja vista que a exploração do xisto, da maneira como tem sido feita, parece acarretar várias externalidades negativas como o metano liberado durante a extração e o potencial comprometimento da qualidade dos recursos hídricos, dentre outros impactos ambientais. A pesquisa que suporta este artigo indica, até o momento, que o preço baixo da energia proveniente do fraturamento hidráulico das rochas betuminosas só é conseguido mediante uso insustentável de recursos naturais. Neste sentido é oportuna a investigação jurídica sobre os custos ambientais de tal exploração,

1 O termo mais técnico do ponto de vista geológico é "gás de folhelho", não "gás de xisto", pois inclui formaçóes geológicas distintas da do xisto que também são exploradas pelo fraturamento hidráulico (fracking). Porém, o termo "gás de xisto" é o mais popularizado e por isso foi adotado neste texto. O Decreto no 8.437, de 22 de abril de 2015 estabelece a seguinte nomenclatura: "Art. 2o Para os fins deste Decreto, adotam-se as seguintes definiçôes: (...) XXIX -recurso não convencional de petróleo e gás natural - recurso cuja produção não atinge taxas de fluxo econômico viável ou que não produzem volumes econômicos de petróleo e gás sem a ajuda de tratamentos de estimulação maciça ou de tecnologias e processos especiais de recuperação, como as areias betuminosas - oilsands, o gás e o óleo de folhelho shale-gas e shale-oil, o metano em camadas de carvão - coalbed methane, os hidratos de metano e os arenitos de baixa permeabilidade - tightsandstones" 
com a consideração de um possível "dumping ambiental" e como tal, sua apreciação pelo Sistema de Solução de Controvérsias da Organização Mundial do Comércio.

\section{Palavras-chave}

Gás de xisto; Gás de folhelho; Hidrocarbonetos não convencionais; Dumping ambiental.

\section{Resumen}

El abaratamiento de la producción de energía a partir de la extracción de hidrocarburos no convencionales, mediante el fracking, está creciendo de manera exponencial en los Estados Unidos y Canadá, con esto baja el precio de los hidrocarburos, que se vuelve más ventajoso en términos económicos y dificultando aún más la competitividad de las fuentes de energía renovables. Sus impactos son de interés comercial, pero también son de gran importancia para el medio ambiente, dado que la exploración de la forma en que se ha hecho, parece ser la causa de varios factores externos negativos, como el metano liberado durante la extracción y el posible deterioro de la calidad de los recursos hídricos, entre otros impactos ambientales. La investigación que apoya este artículo indica, hasta el momento, que el bajo precio de la energía de la fracturación hidráulica de esquisto solo se logra mediante el uso insostenible de los recursos naturales. En este sentido es oportuna la investigación legal de los costos ambientales de esa explotación, con la consideración de un posible "dumping ambiental" y, como tal susceptible de apreciación por el Sistema de Solución de Diferencias de la Organización Mundial del Comercio

\section{Palabras clave}

Gas de esquisto; Gas no convencional; Hidrocarburos no convencionales; Dumping ambiental.

\section{Introdução ${ }^{2}$}

O uso de rochas betuminosas para extrair nafta, óleo combustível, gás liquefeito, óleo diesel e gasolina, não é novidade. Novo é o contexto conseguido pelos EUA e Canadá

2 O presente artigo aborda parte da pesquisa de Doutorado que está sendo realizada por Danielle Mendes Thame Denny, sob orientação da Profa. Dra. Maria Luiza Machado Granziera, na linha de pesquisa Regimes Ambientais: Formaçáo e Criação do Programa de Doutorado em Direito Ambiental da Universidade Católica de Santos. O esforço investigativo aqui descrito tem sido realizado sob os auspícios do Grupo de Pesquisa Energia e Meio Ambiente, criado em 2010, sob liderança dos Doutores Maria Luiza Machado Granziera e Fernando Cardozo Fernandes Rei e dialoga com o Projeto de Desenvolvimento intitulado Tecnologia y Riesgo: La Extraccion de Hidrocarburos No Convencionales Mediante el Fracking. Propuesta de Regulacion Ambientalmente Sostenible, criado em 2014, sob coordenação de German Valencia Martin e com parte da referida pesquisa realizada no Brasil pelos Professores Fernando Cardozo Rei e Rafael Costa Freiria, pesquisadores de referido projeto. O estudo teórico, legislativo e jurisprudencial tem como foco principal o Direito Internacional Ambiental, mas buscará também suporte teórico no Direito Econômico Internacional. 
de preço baixo, com o uso da tecnologia de fraturamento hidráulico que utiliza uma mistura de água, areia e produtos químicos de várias naturezas para perfurar as camadas de xisto e extrair gás natural dos poros rochosos. De acordo com a Administração de Informação de Energia dos EUA (EIA, na sigla em inglês), a participação do xisto na produção total de gás natural americano passou de menos de 5\% há 10 anos para 34\% em $2013 .{ }^{3}$

Os EUA dispóem de uma quantidade significativa de recursos energéticos provenientes da exploraçấo do xisto. Suas reservas estáo em segundo lugar, perdendo apenas para a Rússia em se tratando de óleo e em quarto lugar, perdendo apenas para China, Argentina e Argélia, no tocante ao gás natural. ${ }^{4}$ Essa extensa reserva cumulada com o domínio da tecnologia necessária à exploração desses recursos (horizontal drilling e hydraulic fracturing) têm efeitos na queda vertiginosa dos preços do gás natural e, consequentemente, no rápido crescimento da produção industrial intensiva em energia, como indústria química e de metais, que voltam a procurar os EUA para se instalar.

A facilidade de liquefação e portanto de comércio internacional dessa fonte energética pode impactar de forma significativa o arranjo de mercado energético no mundo e especialmente o do Brasil, pois a capacidade industrial instalada no país já funciona com gás natural, a origem desse gás natural, sendo ou não do xisto, não demanda alterações do parque instalado, tendo em vista que é possível a utilização dos mesmos equipamentos.

O esforço investigativo do qual este texto é parte teve início com entrevistas a especialistas, as quais foram publicadas em formato jornalístico na Revista Ambiente Legal ${ }^{5}$. Nessa oportunidade, concedendo uma das entrevistas, Adriano Pires, diretor do Centro Brasileiro de Infra-Estrutura, afirmou que "o mundo passa por uma grande revolução energética. Há três anos, se pensava que tinha chegado a vez dos renováveis, mas parece que não, que o gás natural vai ser a força motriz da terceira revoluçáo industrial“. José Roberto Mendonça de Barros, outro entrevistado, apontou que o gás de xisto deprime o preço do velho carbono, e se torna mais competitivo do que é hoje. "Petroquímicas brasileiras já se mudaram para os EUA, pois não têm como competir aqui, são 17 dólares em Camaçari e 3 dólares nos EUA" estima.

Nathan Hultman, da Universidade de Maryland, nos Estados Unidos, que também concedeu entrevista na revista supra mencionada, ponderou que o gás natural vai ter impacto, mas não vai inviabilizar o mercado para os combustíveis limpos. Ele citou exemplos como: 1. as novas usinas de energia americanas já se submetem a limites de

3 Cálculo feito pela EIA e disponível no site http://www.eia.gov/todayinenergy/detail.cfm?id=18951

4 Relatório elaborado pela EIA e disponível no site http://www.eia.gov/todayinenergy/detail.cfm?id=11611

5 Gás de xisto ameaça renováveis. Fonte de energia do momento derruba o preço do 'velho carbono', afirmam especialistas. Revista Ambiente Legal, AICA, São Paulo, 2013. Disponível em: < http://www. ambientelegal.com.br/gas-de-xisto-ameaca-renovaveis/>. 
emissão, porque o CO2 é considerado um poluente; 2. há um teto de emissôes aplicável ao transporte veicular e 3. o State Renewable Portfolio Standards já obriga a observância de uma porcentagem mínima de fontes renováveis na energia elétrica em 30 dos 50 estados americanos.

Inclusive, caberia, para esse tipo de exploração não convencional de gás natural se submeter a padróes técnicos e mecanismos de monitoramento muito mais cautelosos, mas por uma questão política, em 2005, por meio da Lei das Exceçóes ${ }^{6}$, o então presidente George Bush, priorizando o objetivo dos EUA em se tornar energeticamente independente, isentou as empresas produtoras de gás não convencional da obrigação de atenderem aos dispositivos ambientais, inclusive os previstos no Clean Water Act5 ${ }^{7}$, a lei americana de proteção aos recursos hídricos.

Esse ato político possibilitou juridicamente a desenfreada implementação de diversos campos de extração de gás não convencional nos EUA, favorecendo corporaçôes do setor de óleo/gás, porém com diversos efeitos deletérios no âmbito social, econômico e ambiental, conforme pode ser verificado do documentário Gasland (FOX, 2010) ${ }^{8}$ e em inúmeras violaçóes, conforme constatou o National Resources Defense Council e o FracTracker Alliance, em estudo que investigou as operaçóes de fraturamento hidráulico para monitorar não só os casos de efeitos deletérios como também a falta de publicidade e a necessidade de regulação mais efetiva (NRDC/FTA, 2015).

Atualmente apenas EUA, Canadá e China9 exploram comercialmente o gás de xisto, mas a Rússia, a China e o próprio Brasil possuem grandes reservas do recurso. Para o vice-diretor do Instituto de Eletrotécnica e Energia da Universidade de São Paulo (USP), Colombo Celso Gaeta Tassinar em entrevista concedida na revista acima referida, "o potencial brasileiro seria superior a 6,4 trilhóes de metros cúbicos, ou seja, entre as 10 maiores reservas do mundo" ${ }^{10}$. Para ele, quando esses recursos forem explorados, as indústrias que utilizam gás natural em sua produção serão beneficiadas com a queda do custo do

6 Ato legal emanado do executive americano com o objetivo de isentar a indústria de fraturamento hidráulico de muitas regulaçóes ambientais entre elas o Safe Drinking Water Act; o Resource Conservation and Recovery Act; o Emergency Planning and Community Right-To-Know Act; o Clean Water Act; o Clean Air Act; o Comprehensive Environmental Response, Compensation, and Liability Act; e o National Environmental Policy Act. (BRADY, 2011: 3-4)

7 O Clean Water Act proíbe, nos Estados Unidos, as atividades que envolvam impactos em aquíferos que servem para abastecimento humano.

8 Documentário dirigido por Josh Fox em 2010 que aborda o dilema enfrentado pelos proprietários rurais que se veem diante da oferta lucrativa de ceder o uso de suas terras para as empresas de energia e o inesperado impacto ambiental danoso que essa atividade passa a representar em suas vidas, evidenciando uma política governamental que prioriza o capital em detrimento da qualidade de vida das pessoas.

9 Dados levantados pela EIA e disponível no site: http://www.eia.gov/todayinenergy/detail.cfm?id=19991

10 Gás de xisto ameaça renováveis. Fonte de energia do momento derruba o preço do 'velho carbono', afirmam especialistas. Revista Ambiente Legal, AICA, São Paulo, 2013. Disponível em: < http://www. ambientelegal.com.br/gas-de-xisto-ameaca-renovaveis/ > . 
combustível e terão aumento de competitividade. Essa informação é relevante, na medida em que aponta, se verdadeira para uma verdadeira revolução na matriz energética contemporânea, porém com graves custos ambientais que, se não forem internalizados pelos exploradores, deixará uma marca deletéria nessa nova dimensão energética.

Ainda é difícil avaliar os riscos que o gás de xisto representa, conclui Luis Roberto Pogetti, presidente do Conselho de Administração da Copersucar, maior produtora de açúcar e etanol do mundo. "Sem dúvida há um novo panorama, mas ainda haverá muitas discussóes ambientais e sobre a viabilidade da manutençáo dos preços baixos no longo prazo" (informação verbal ${ }^{11}$ ). Ademais, para ele, o fato de não ser energia limpa deve tirá -lo de uma necessária agenda de futuro que reconheça a importância estratégica de manter combustível limpo na matriz energética mundial.

O presente artigo tem como hipótese constatar, por análise teórica e estudo de caso, que a forma com que tem agido a indústria de extração de hidrocarboneto não convencional, quando implementa a tecnologia de fraturamento hidráulico atualmente é dumping ambiental. Para tanto, os objetivos específicos serão apontar 1. as especificidades técnicas dessa tecnologia que vão interferir na análise jurídica e também 2. casos em que foram documentadas inadequaçóes ou falta de publicidade a respeito.

O objetivo geral será mostrar que pode ser identificada negligência com a preservação do meio ambiente e a legislação ambiental dos países que adotam essa tecnologia, principalmente no tocante às normas voltadas para proteção das águas, sobretudo as mais frágeis, que são as subterrâneas, o que fundamenta o tratamento jurídico como dumping ambiental. A justificativa, fundada na corrente epistemológica dialética, é contribuir para a identificação de alguns dos conflitos de interesses intrínsecos ao uso dessa nova tecnologia para atender a objetivos das políticas energética e de soberania, muitas vezes em detrimento da proteção ao meio ambiente e da participação da população envolvida.

\section{Desenvolvimento}

O método de fratura hidráulica consiste na perfuração de vários poços em uma determinada área, até as camadas dos folhelhos das rochas betuminosas, normalmente encontradas em grandes profundidades, como as superiores a dois mil metros. Para a perfuração e fraturamento são utilizadas injeçóes, sob altas pressóes, de uma mistura de água, areia e um coquetel de produtos químicos nem sempre conhecidos pois a solução de fraturamento é protegida por patente em nome de cada indústria que atua nesse mercado. A solução de fraturamento precisa depois ser bombeada para fora da rocha para receber o devido tratamento ou disposição final adequada.

11 Análise feita por Luis Roberto Pogetti, no Ethanol Summit 2013, em São Paulo / SP 
Com a abertura dos poços e o fraturamento da rocha, os gases presentes nas porosidades dos folhelhos (metano, propano, nitrogênio, dióxido de carbono, entre outros) e óleo bruto são liberados para a superfície, sendo cada poço normalmente conectado a uma usina para pré-refino e a um gasoduto para transmissão desse gás para uma refinaria de grande porte. Esse conjunto de poços é denominado campo de extração de gás nãoconvencional por fraturamento hidráulico o qual tende a ter, em média, um prazo economicamente útil de 2 a 3 anos.

Depois desse prazo, o gás remanescente, que não apresenta viabilidade econômica para captação, normalmente é queimado no próprio local (FOX, 2010), até que haja condiçôes para o selamento do poço com concreto. Isso pode acontecer após um longo período, uma década depois de finalizada a exploração econômica do gás em um determinado local, por exemplo, mas caso não seja feita essa migração de forma planejada e monitorada pode durante todo esse período causar impactos sócio-ambientais negativos.

Durante a sondagem e perfuração dos poços, devido à grande profundidade, há a necessidade de uso de um volume muito grande de recursos hídricos e de químicos. A técnica é semelhante à extração de petróleo no pré-sal, com a diferença que no mar a água é abundante e no continente muitas vezes esse recurso tem de ser levado até o campo de extração por caminhóes pipas, o que contribui para a emissão de gases de efeito estufa.

Os fluidos de perfuração correspondem a um coquetel químico variável de acordo com a empresa que realiza a prospecção. Alguns dos químicos são comprovadamente lesivos à saúde humana, muitos sendo, inclusive cancerígenos. Assim, se essa composição química vazar para fora do duto de perfuração pode contaminar o solo e as águas subterrâneas dos aquíferos comprometendo o consumo humano (CNHNY, 2014).

Depois de perfurado o poço e instalados os dutos, é feita uma injeção de solução de fraturamento para dissolver as rochas betuminosas. Da mesma forma que os fluídos de perfuração, o potencial de contaminação química do solo e dos lençóis freáticos é muito grande, haja vista a variedade de produtos químicos e orgânicos considerados tóxicos à saúde que precisa ser utilizada.

A técnica e a regulamentação utilizada até o momento para prevenir que haja vazamentos ainda não se mostram suficientemente seguras (NRDC/FTA, 2015). Além disso, a estimativa do risco é de grande complexidade uma vez que depende do alcance das plumas de gás ou fluido que vazaram, das concentraçóes de substâncias toxicas, da proximidade com poços artesianos e dos aspectos geo e hidrológicos da área.

De qualquer forma, de todo o fluido injetado, apenas em torno de $50 \%$ consegue ser bombeado de volta para receber o devido tratamento ou disposição final ambientalmente adequada. A soluçáo que consegue ser recuperada fica temporariamente estocada em piscinas de acumulação, sobre as quais ainda não há uma regulamentação padronizada 
para evitar infiltraçóes e transbordamentos. Principalmente nos períodos chuvosos, essas bacias de contenção temporária ficam susceptíveis a contaminar solo e água em virtude de possíveis vazamentos.

O próprio transporte desses resíduos perigosos também representa um risco intrínseco. Mesmo havendo um conjunto de normas técnicas e de regulamentação específica para transporte de substâncias perigosas, ainda há possibilidade de acidentes nas rodovias, nas estações de tratamento de efluentes ou na disposição final, em incineradores ou aterros sanitários em tanques selados.

Além disso, cada poço de fraturamento hidráulico possui uma usina para pré-refino, na qual o gás retirado do poço é submetido a altas temperaturas para reduzir a umidade e os teores de compostos orgânicos voláteis que estavam condensados junto com o gás liberado das rochas betuminosas. Esses resíduos formam um condensado de gás que precisa ser armazenado em tanques próprios ou ser queimados nas estaçóes finais de refino. Se vazarem para a atmosfera para o solo ou para a água geram contaminação.

O próprio gás pode ser o contaminante poluindo os aquíferos com metano, propano, óxido de carbono e outros gases comprometendo a saúde humana e a qualidade dos recursos inclusive podendo tornar a água explosiva, comprometendo a segurança dos dutos dos sistemas de abastecimento humano. A qualidade do ar também fica comprometida em virtude da alta densidade de gases e compostos voláteis nas regióes próximas aos campos de fraturamento. Essas são algumas entre outras muitas formas possíveis de impacto ambiental.

\section{Sociedade de Risco}

Essa questão acima descrita remete o pesquisador para a questão da sociedade de risco, na qual o desenvolvimento tecnológico e os padróes de consumo da atualidade têm um preço, que é a crescente degradação da biosfera. Daí a necessidade de uma análise muito detalhada dos impactos e do custo socioambiental que tais empreendimentos impóem.

Sobre essa matéria, antes de tratar da sociedade de risco, cabe uma reflexão principiológica acerca da ecologia, nos seguintes termos:

"Ecologia é doutrina da casa (óikos), do mundo. A habitação humana é esta "casa", que é o ambiente natural. A palavra insinua que o ambiente é como uma casa para o homem, onde ele se reconhece como esperado e aceito, onde encontra não só um sistema de serviços de que a vida humana precisa, mas também os significados constitutivos da vida. (...) A ecologia, como articulação recente das ciências biológicas, define a vida (bios) como princípio autopoiético de síntese de elementos dispersos, e se ocupa da História natural, isto é, do destino de cada uma das espécies e de sua capacidade auto-organizativa (vida) em relação ao destino de 
outras formas de vida, presentes no respectivo ambiente." (DENNY, E. A, 2003: 51)

O termo "sociedade de risco" de Ulrich Beck (1998) refere-se ao aspecto da História social moderna pelo qual os custos do progresso econômico começam a destruir o Estado de bem-estar que ele mesmo contribuiu para construir. Não são perigos espontâneos, mas produzidos pela sociedade e surgem das próprias forças produtivas. Ciência, técnica e economia produzem riscos que crescem à medida que aumentam as condiçóes materiais da existência humana.

Os conflitos da sociedade industrial clássica constituíam-se de um caráter econômico, sem uma contrapartida relativa a direitos sociais. Tratava-se de maximização dos lucros das empresas, da relação entre tempo de trabalho e tempo livre, da quantia correspondente à mais valia. Tais conflitos foram contemplados com uma evolução legislativa, sobretudo a respeito dos direitos sociais, implementados no século XX.

Contudo, surgiram novos conflitos ao longo do tempo. Na sociedade de consumo, com a distribuição dos custos dos danos ecológicos, tornou-se necessária a fixação de limites para o lançamento de resíduos tóxicos, mitigando o potencial dano no meio ambiente, entre outras questóes. Nessa linha,

"Em suma, a questão ambiental não pode ser tratada só sob o ponto de vista econômico. A análise custo/ benefício tende a esquecer os interesses não monetários da relação do homem com o ambiente. $\mathrm{O}$ critério de justiça é o que deve estabelecer a relação entre o desenvolvimento econômico e o ambiente sadio, procurando a síntese e o equilíbrio entre o desfrutar e o poupar, o inovar e o conservar, o fabricar e o eliminar, o trabalhar e o gozar... "(DENNY, E. A, 2003: 54)

Os riscos, portanto, são compartilhados e ninguém, nem aqueles em melhor situação financeira conseguem ficar ilesos, "a miséria é hierárquica, o $\operatorname{smog}^{12}$ é democrático" (BECK, 1998: 26). Os danos à natureza foram socializados, politizados e, com isso, surgiram novas exigências, traduzidos na necessidade de proteçáo aos direitos difusos ${ }^{13}$. $\mathrm{O}$ impacto, pois, é geral e a poluição afeta um número indeterminado de pessoas, independentemente de classe social.

Além disso, muitas vezes, os riscos só podem ser conhecidos e demonstráveis com instrumentos e técnicas muito sofisticados. Exigem, portanto, uma alteração substancial no ordenamento jurídico, que precisa exigir aprofundamento nos estudos ambientais,

12 Smog é um neologismo resultante da combinaçáo de smoke (fumaça) com fog (nevoeiro), designa a poluição atmosférica densa.

13 Direitos difusos são transindividuais indivisíveis, pertencem a indivíduos indetermináveis ligados entre si por uma circunstância de fato. 
publicidade e participação popular, coibindo-se a violação de direitos difusos, pois são inaplicáveis os princípios tradicionais da causalidade e da responsabilidade, por exemplo, dada a dificuldade da determinaçáo dos efetivos responsáveis pelos danos e pela consequente reparação.

Torna-se necessária uma revisão paradigmática do desenvolvimento técnico, uma análise do problema que consiga retardar, eliminar ou mitigar os efeitos não desejados e as ameaças de catástrofes. A ética, a política, a economia e a comunicação precisam ser adaptadas à sociedade de risco para poder dar respostas inovadoras aos problemas. Articular participação de atores não convencionais como da sociedade civil e reconhecendo a relevância de pequenas açôes individuais praticadas no dia a dia, com as quais se possa construir um novo paradigma que confira valor à sustentabilidade.

\section{Princípios da Precaução e da Prevenção ${ }^{14}$}

Os termos precaução e prevenção, apesar de parecerem sinônimos, são tratados de forma diferente pela doutrina ambiental. O princípio da precaução justifica a proibição de uma determinada atividade face a ausência de certeza científica sobre os potenciais danos.

14 Esse dilema prevenção ou precaução é justamente o objeto do Projeto de pesquisa Tecnologia e risco: a extração de hidrocarbonetos não convencionais mediante fraturamento hidráulico, coordenado por Germán Valencia Martín, na Universidade de Alicante, na Espanha com vários pesquisadores, entre eles, os brasileiros Fernando Cardoso Rei e Rafael Costa Freiria. A seguir a descrição do objetivo da pesquisa:

"La extracción de hidrocarburos no convencionales por medio de la técnica de la fractura hidráulica o fracking está despertando en el mundo entero, y también en España, una considerable polémica, por sus temidas repercusiones ambientales, valoradas hasta el momento a partir básicamente de la experiencia norteamericana. Controversia que ha alcanzado ya en España al plano normativo, con distintas leyes autonómicas de carácter prohibitivo, y la inmediata, pero tal vez insuficiente, reacción por parte del legislador estatal. La situación jurídica en países de nuestro entrorno también obedece a las mismas coordinadas, es decir, entre la prohibición y la permisividad en virtud de la legislación específica de hidrocarburos. El análisis de sus impactos ambientales y sobre la salud pública marcan el momento actual tanto en la Unión Europea como en el ámbito internacional. Desde la perspectiva jurídica el objeto de este proyecto es importante, de rigurosa actualidad y, por su novedad, todavía no suficientemente estudiado. Bajo las indicadas circunstancias, nuestra hipótesis de partida es que, dejando a un lado posturas extremas, puede haber una regulación ambientalmente sostenible de la extracción de hidrocarburos por medio de la técnica del fracking, que permita su empleo no traumático si las consideraciones de política energética así lo demandan, con tal de que dicha regulación se construya correctamente, a partir de un análisis completo y racional de todas las implicaciones ambientales de dicha técnica y consiguientemente de todos los subsectores normativos afectados."

O grupo, dessa forma, constata que há muita polêmica, principalmente em virtude da forma como foi feita a exploração nos EUA. Essas controvérsias fazem com que alguns países europeus, inspirados na mesma diretiva europeia, proíbam e outros, permitam o uso dessa tecnologia para extraçáo de energia. Em virtude disso, adota como hipótese a ser comprovada ou refutada pela pesquisa do grupo, a possibilidade de haver uma regulamentação eficiente para garantir a extração de hidrocarbonetos não convencionais de forma sustentável, a partir do princípio da prevenção que pressupóe uma análise completa e racional de todos os impactos ambientais decorrentes do uso dessa tecnologia. 
"A implementação do princípio da precaução não tem por finalidade imobilizar as atividades humanas. Não se trata da precaução que tudo impede ou que em tudo vê catástrofes ou males. O princípio da precaução visa à durabilidade da sadia qualidade de vida das geraçóes humanas e à continuidade da natureza existente no planeta" (MACHADO, 2011: 76)

Já o princípio da prevenção busca a compatibilização entre a atividade potencialmente impactante e a proteção ambiental, mediante estudo abrangente para serem conhecidos todos os riscos envolvidos e, com base nisso, seja feito um licenciamento exigindo o comprimento de condicionantes mitigando, assim, ao máximo tais riscos.

\begin{abstract}
"Sem informação organizada e sem pesquisa não há prevenção. A aplicação do princípio da prevenção comporta, pelo menos, doze itens: 1) identificação e inventário das espécies animais e vegetais de um território, quanto à conservação da natureza; 2) identificação das fontes contaminantes das águas e do ar, quanto ao controle da poluição; 3) identificação e inventário dos ecossistemas, com a elaboração de um mapa ecológico; 4) planejamento ambiental e econômico integrados; 5) ordenamento territorial ambiental para a valorização das áreas de acordo com a sua aptidão; 6) Estudo de Impacto Ambiental; 7) prestação de informaçôes contínuas e completas; 8) emprego de novas tecnologias; 9) autorização ou licenciamento ambiental; 10) monitoramento; 11) inspeçấo e auditoria ambientais; 12) sançôes administrativas ou judiciais." (MACHADO, 2011:99)
\end{abstract}

O custo da prevenção tende a ser menor que o da reparação e alguns danos são irrecuperáveis, mas se os riscos forem conhecidos, previsíveis, podem e devem ser mitigados, pressupondo, também, necessárias medidas cautelares para impedir a continuidade de eventuais atividades lesivas ao meio ambiente. Porém, se houver dúvida, se os riscos não forem conhecidos, ou houver suspeita da irreversibilidade de um eventual dano, a cautela indica que seja proibida a atividade, afinal, na dúvida é melhor não se correr um risco que possa comprometer a sadia qualidade de vida inclusive das geraçôes futuras.

"Em caso de certeza do dano ambiental, este deve ser prevenido, como preconiza o princípio da prevenção. Em caso de dúvida ou de incerteza, também se deve agir prevenindo. Essa é a grande inovação do princípio da precaução. A dúvida científica, expressa com argumentos razoáveis, não dispensa a prevenção. (...) Aplica-se o princípio da precaução ainda quando existe a incerteza, não se aguardando que esta se torne certeza." (MACHADO, 2011: 85)

O objetivo do princípio da prevenção é justamente buscar conciliar a atividade potencialmente danosa com a devida proteção ambiental. Assim, havendo análise prévia dos impactos que um determinado empreendimento possa causar à saúde e ao meio ambiente, 
é possível, desde que adotadas medidas compensatórias, condicionantes e mitigadoras, assegurar sua atividade inclusive com os benefícios econômicos dela decorrentes.

E trata-se de um processo dinâmico, conforme avança a tecnologia maior é a capacidade de conhecer e monitorar os riscos e melhores são as formas de controle. $\mathrm{O}$ que num dado momento histórico precisa ser evitado, com a evolução tecnológica, em pouco tempo pode se tornar relativamente seguro.

"A segurança, como a pobreza, se constitui em um estado relativo, que
pode variar em grande medida em função da cultura, do tempo, do lugar,
essa segurança continua sempre sendo um ideal inalcançável (...) Em ou-
tras palavras: as necessidades, exigências, possibilidades e competências
de prevenção aumentam de forma recíproca no curso do processo de ci-
vilização (...) a sociedade da prevenção acompanha de forma silenciosa a
sociedade de risco" (MAY, 2012: 321-322)

Assim, pelo princípio da prevenção, em um sistema de exploração de gás pelo fraturamento hidráulico, os riscos e vulnerabilidades precisam ser conhecidos previamente, os eventuais danos serem possíveis de ser identificados, avaliados e portanto mitigados por medidas de controles adequadas que possibilitem ação rápida e eficaz para reduzir ao máximo o risco de qualquer forma de poluição.

Se houver conhecimento técnico científico que permita conhecer todos esses potenciais riscos e for possível fazer uma regulação eficiente para mitiga-los, a atividade de fraturamento hidráulico deve ser licenciada, conforme o princípio da prevenção. Contudo, se estudos técnicos científicos apontarem para uma imprevisão muito grande ou um risco de irreversibilidade dos danos, a atividade precisa ser proibida, seguindo o princípio da precaução. Pelo menos até que os avanços tecnológicos permitam que a imprevisibilidade e a irreversibilidade diminuam.

\section{Recomendação da Comissão Européia}

A Comissão Europeia elaborou uma recomendação aos Estados europeus contendo os padróes básicos a serem seguidos pelas legislações nacionais para regular a exploração de gás natural pela tecnologia de fraturamento hidráulico, garantindo a preservaçáo do meio ambiente, o uso eficiente dos recursos naturais e respeitando o direito à informação dos cidadão.

Diferentemente das Diretivas, as Recomendaçóes não têm caráter vinculativo, apenas sugerem condutas, sem todavia implicar em qualquer obrigação legal. Dessa forma, essa específica recomendação sugeriu o prazo de adequação das legislaçóes dos Estados para julho de 2014 e agora prevê que anualmente em dezembro haja entrega de um relatório das medidas adotadas pelos Estados no tocante a essa recomendação. 
Em linhas gerais a Recomendação orienta tanto para que haja planejamento estratégico e estudo de impacto ambiental a tempo da população afetada poder participar desde o início do projeto, como para que sejam adotados instrumentos como autorizaçóes, licenças e outorgas pelo poder público para exigir dos operadores o uso das melhores técnica disponíveis, para mitigar ao máximo o risco.

Nos EUA e Canadá não foi encontrado até o momento nenhuma orientação legislativa similar à europeia, pelo contrário, cada Estado exerce sua autonomia federativa para permitir, regular ou proibir o fraturamento hidráulico da maneira que lhe for melhor conveniente.

\section{No Brasil}

A importância do gás natural para a matriz energética brasileira tem crescido, Ministério das Minas e Energia constata que a indústria do gás natural cresceu em 2014 de 89,64 para 100,00 milhóes de $\mathrm{m}^{3} / \mathrm{dia}$ (MME, 2015:29), em virtude da demanda para as termelétricas $(+21,7 \%)$ e para as indústrias $(+4,7 \%)$. Com esse aumento, estão previstos maiores investimentos na infraestrutura de distribuição, principalmente via gasodutos, nesse sentido foi aprovada pela Portaria MME no 128, de 26 de março de 2014, o Plano Decenal de Expansão da Malha de Transporte Dutoviário do País - PEMAT 2022, com base em estudos de expansão realizados pela Empresa de Pesquisa Energética.

Para suprir esse aumento de demanda houve aumento da exploração nacional e intensificação das parcerias internacionais. Por exemplo o Segundo Aditivo ao Memorando de Entendimento (do inglês MoU - Memorandum of Understanding) em matéria de intercâmbio de energia, com vigência até o final de 2015 e celebrado entre Brasil e Argentina, prevê livre trânsito de gás natural brasileiro pela malha de gasodutos da Argentina. Essa cláusula viabilizou o suprimento à usina termelétrica de Uruguaiana, localizada no Rio Grande do Sul e possibilitou um total de geração de 322,08 GWh utilizando gás natural brasileiro (MME, 2015:28).

O fato desse gás natural provir de fontes convencionais ou não convencionais como o gás de xisto, não altera a capacidade industrial instalada. $O$ gás natural proveniente de fontes não convencionais podem, portanto, ser transportado pelos mesmos gasodutos e serão utilizados nas mesmas máquinas que operam atualmente com gás proveniente de fontes convencionais.

Em virtude disso, o governo federal, na $12^{\circ}$ rodada de leilão de gás, em 28 de novembro de 2013, previu 240 blocos a serem outorgados ao poder privado para exploraçáo do gás de xisto, em várias áreas do país, inclusive em algumas com incidência do aquífero Guarani. Porém, o edital não encontra respaldo na política energética brasileira até 2030, documentada por dois documentos: a Matriz Energética Nacional e o Plano Nacional de 
Energia 2030. Em nenhum deles há referência ao gás não convencional. Sendo assim, não faz sentido ele ser integrado repentinamente à matriz energética brasileira sem qualquer justificativa específica.

O edital desconsiderou, também, o parecer técnico elaborado pelo Grupo de Trabalho Interinstitucional de Atividades de Exploração e Produção de Óleo e Gás - GTPEG n. 03/2013, do Ministério do Meio Ambiente (MMA, 2013), cuja atribuição é justamente assessorar o setor de petróleo e gás no tocante às medidas ambientais prévias a serem tomadas antes da concessão da outorga.

O parecer recomendava um estudo mais efetivo e um envolvimento maior da população, antes da tomada de decisão pela exploração, sugerindo a Avaliação Ambiental de Área Sedimentar - AAAS como instrumento para verificar os impactos e riscos ambientais envolvidos nessa atividade, para que seja possível a regulamentação e o monitoramento e, com isso, uma atuação segura para o meio ambiente e para a saúde humana.

Fundamentando no princípio da precaução e nessas ilegalidades que demonstram ser precipitada a autorização da tecnologia de fraturamento dentro deste contexto, o Ministério Público Federal de vários estados propuseram ação civil pública contra a União Federal e a ANP - Agência Nacional do Petróleo, Gás Natural e Biocombustíveis.

TRF4-5012993-50.2014.4.04.0000-AI - TRF4 - TRIBUNAL REGIONAL FEDERAL DA 4ª REGIÃO.

JF/FLR-0005610-46.2013.4.01.4003-ACP- JF/FLR - JUSTIÇA FEDERAL - SUBSEÇÃO JUDICIÁRIA DE FLORIANO-PI.

JF-BA-0030652-38.2014.4.01.3300-ACP - JF-BA - JUSTIÇA FEDERAL - SEÇÃO JUDICIARIA DO ESTADO DA BAHIA.

JF-PPR-0006519-75.2014.4.03.6112-ACP - JF-PPR - JUSTIÇA FEDERAL - 12a SUBSEÇÃO JUDICIÁRIA - PRESIDENTE PRUDENTE/ SP.

Com essas medidas, foram conseguidas liminares que suspendem os efeitos da $12^{\text {a }}$ rodada de licitações dos blocos para a exploração de gás pelo uso da técnica de fraturamento hidráulico e proíbem a ANP de realizar novas licitaçôes que prevejam o uso do fraturamento hidráulico, até que sejam feitos estudos exaustivos demonstrando a viabilidade socioambiental do uso desta técnica.

\section{Dumping Ambiental}

O Acordo Antidumping, da Organização Mundial do Comércio, em seu Art. 2º, define dumping como sendo a fixação arbitrária de um preço de venda inferior ao valor normal. O conceito de dumping ambiental decorre dessa definição clássica de dumping 
comercial, assim, praticar preços que desconsiderem os reais custos, inclusive os ambientais, pode ser tomado como um caso de dumping.

\section{Artigo 2}

Determinação de Dumping

1. Para as finalidades do presente Acordo, considera-se haver prática de dumping, isto é, oferta de um produto no comércio de outro país a preço inferior ao seu valor normal, no caso de o preço de exportação do produto ser inferior àquele praticado, no curso normal das atividades comerciais, para o mesmo produto quando destinado ao consumo no país exportador. ${ }^{15}$

Apesar de não estar previsto expressamente no Acordo Antidumping, da Organização Mundial do Comércio, a construção teórica e jurisprudencial identifica o dumping ambiental como a oferta de produto no comércio internacional com um preço que desconsidera os custos ambientais decorrentes da sua produção e portanto concorrem deslealmente com os produtos que foram feitos respeitando as exigências ambientais.

Portanto, dizer que a indústria de extração de gás, quando implementa a tecnologia de fraturamento hidráulico pratica dumping ambiental, significa afirmar que os produtores não agem de maneira a preservar o meio ambiente, ou a legislaçáo ambiental do país onde se dá a extração é ineficiente para garantir uma produção sustentável. Dessa forma, os baixos preços do gás, quando são adquiridos pelos consumidores, refletiriam a não interiorização dos custos ambientais no momento da produção do combustível.

Contudo, o modelo de disputas comerciais da OMC parece não dispor de ferramentas jurídicas suficientemente eficazes para analisar casos de regulamentação positiva na relação comércio e meio ambiente. O próprio Acordo Antidumping da OMC prevê que os Estados Membros adotem procedimentos investigatórios para combater o dumping realizado pelo setor privado e que cause dano comprovado ao comércio. Essa investigaçáo e não o dumping em si que é questionavel perante a OMC.

\footnotetext{
"Raras vezes, na maior parte do século que há pouco terminou, cruzaram-se os caminhos do comércio internacional e da preservação do meio ambiente. Os artífices da normatividade em ambas as esferas percorreram, quase sempre, vias próprias, devotados aos problemas específicos da área a ser regulada." (AMARAL JR., 2011: 137)
}

15 Texto original do Acordo Antidumping, da Organização Mundial do Comércio, em seu "Art. 2.1 For the purpose of this Agreement, a product is to be considered as being dumped, i.e. introduced into the commerce of another country at less than its normal value, if the export price of the product exported from one country to another is less than the comparable price, in the ordinary course of trade, for the like product when destined for consumption in the exporting country." traduzir 
"As diferenças se manifestam, inclusive, na linguagem empregada: o termo proteção guarda, via de regra, um sentido negativo para quem trabalha com o comércio internacional e uma conotação positiva para os ambientalistas." (AMARAL JR., 2011: 141)

Daniel Esty identifica um conflito de paradigmas entre quem atua com comércio internacional e os ambientalistas. Os liberais veem a aplicação de medidas ambientais ao comércio como uma ameaça à harmonia do livre comércio internacional e os ambientalistas, por sua vez, apontam que a maximização do lucro ignora os custos dos impactos ao meio ambiente e é incapaz de quantificar em moeda o valor que os recursos naturais representam para a sociedade (ESTY, 1994:42) ${ }^{16}$.

Apesar desse conflito de paradigmas, há alternativas previstas no arcabouço legal comercial para fomentar a proteção ao meio ambiente, principalmente por regulação negativa. Os Estados Membros estão autorizados a colocar medidas restritivas ao comércio para proteger seu meio ambiente. Seria o caso dos subsídios não acionáveis para fomentar energias renováveis, por exemplo.

"A abordagem geralmente adotada pela OMC reconhece que certo nível de restrição ao comércio pode ser necessário para o cumprimento de alguns objetivos de política pública, desde que duas condiçóes sejam preenchidas: (i) a medida deve ser coberta por uma das exceçôes do Art. XX do GATT 94; e (ii) a medida não deve implicar prática de discriminação arbitrária e injustificável, ou restrição dissimulada ao comércio internacional.” (THORSTENSEN, 2013:L)

Outra possibilidade seria acionar os mecanismos previstos nos Acordos Preferenciais de Comércio, já que na maioria deles há determinaçóes de cunho ambiental. Os padróes regulatórios ambientais exigidos pelos acordos firmados com EUA e Europa são os mais altos, inclusive. Contudo, dado o fato de as exceçóes ambientais aplicáveis ao fraturamento hidráulico ter legitimidade uma vez que emanado do poder executivo, haverá o contra argumento de estar sendo obedecida a legislação nacional e dessa forma tentar-se-á afastar a aplicação das previsóes sobre meio ambiente.

16 “a) Without environmental safeguards, trade may cause environmental harm by promoting economic growth that results in the unsustainable consumption of natural resources and waste production; b) Trade rules and trade liberalization often entail market access agreements that can be used to override environmental regulations unless appropriate environmental protections are built into the structure of the trade system; c) Trade restrictions should be available as leverage to promote worldwide environmental protection, particularly to address global or trans boundary environmental problems and to reinforce international environmental agreements; d) Even if the pollution they cause does not spill over into other nations, countries with lax environmental standards have a competitive advantage in the global marketplace and put pressure on countries with high environmental standards to reduce the rigor of their environmental requirements." (ESTY, 1994:42) 
"No caso dos APCs assinados pelos Estados Unidos e pela União Europeia, encontram-se, em geral, capítulos específicos sobre meio ambiente; (...) Esta tendência dos APCs em regulamentar a área de meio ambiente, de forma cada vez mais substantiva e vinculante, é um processo notável no caso da União Europeia, (...) Os acordos classificados como de "terceiro grau", ou seja, aqueles com compromissos mais detalhados e vinculantes, como são aqueles dos Estados Unidos e os assinados pela União Europeia posteriores a 2000 - por exemplo, União Europeia- Chile e União Europeia-Coreia -, detalham melhor os objetivos de forma que, além da cooperação, também se preocupam em delinear mais claramente como as partes podem definir o que se chama no jargáo internacional de "level playing field”, ou seja, um padrão mínimo regulatório que desfavoreça o recurso às flexibi- lidades regulatórias para gerar vantagens competitivas entre aqueles entes públicos ou privados que operam no comércio internacional, (...) Por esta razão, os acordos indicam explicitamente o compromisso das partes em adotarem políticas de proteção ao meio ambiente, assim como de se comprometerem a respeitar os padróes regulatórios já estabelecidos nacionalmente, sem que as partes possam criar exceçōes ad hoc a fim de favorecer a competitividade de determinadas empresas. Tais acordos também explicitam o compromisso entre as partes de não recorrerem à regulamentaçáo ambiental com efeitos protecionistas e que limitem o fluxo de comércio e/ou investimento entre as partes. Nesses acordos, há, porém, sempre a referência explícita de respeito à legislação nacional, garantindo a cada uma das partes no acordo a soberania para determinaçáo de suas prioridades na regulamentaçáo ambiental, a partir dos compromissos mínimos indicados no acordo." (BALDIN, 2012: 300)

A inexistência de sançóes específicas possíveis de serem aplicadas no caso de descumprimento das cláusulas ambientais dos Acordos Preferenciais de Comércio também é um obstáculo. Acabam sendo levados aos mecanismos de solução de controvérsias apenas violaçôes expressas a legislação doméstica do próprio país.

"Os acordos dos Estados Unidos, como indicado anteriormente, são aqueles que seguem um modelo e definem procedimentos bastante detalhados e particulares para o capítulo de meio ambiente. Em todos os capítulos sobre meio ambiente dos cinco acordos analisados dos Estados Unidos, consta um procedimento específico de consultas que as partes podem solicitar em relação a quaisquer dos dispositivos do capítulo, ao secretariado do acordo ou aos conselhos específicos que gerenciam o acordo. Há procedimentos e prazos previstos para estas consultas, porém não há referência a qualquer tipo de sanção possível no caso de se constatar o descumprimento do acordo por uma das partes. Contudo, os dispositivos mais relevantes, em geral, relativos à legislação doméstica e suas formas de implementação, exclusivamente, podem ser levados ao sistema geral de solução de controvérsias previsto no acordo. Por isto, a indicação de que 
os mecanismos de solução de controvérsias é parcialmente aplicável ao capítulo sobre meio ambiente.”(BALDIN, 2012: 308)

Além do conflito paradigmático mencionado acima, a posição política do Brasil com relação à implementação das previsóes de comércio internacional no tocante a meio ambiente tem sido sempre de resistência, desde o lançamento da agenda ambiental na OMC, o Brasil assume a liderança do grupo de países em desenvolvimento resistentes, em parte porque a área de meio ambiente já tem um regime jurídico de proteção estruturado a parte da OMC e também em vista do receio de medidas socioambientais serem distorcidas e usadas para proteger indevidamente os mercados dos países desenvolvidos.

Dessa maneira, é muito remota a possibilidade de o Itamaraty tomar alguma posição mais contundente, exigindo dos países que atualmente exploram o fraturamento hidráulico o comprometimento com medidas socioambientais responsáveis. É improvável mas possível. E, inclusive, se houvesse alguma articulação política nesse sentido, mesmo antes de qualquer apreciação pelo sistema de solução de controvérsias da OMC, o dano à reputação das empresas provavelmente já teria impactos eficazes em incentivar o maior engajamento socioambiental.

A reputação organizacional, para Roberts e Dowling, seria um ativo intangível com potencial de criação de valor, ela agrega atributos organizacionais, criados ao longo do tempo, que refletem o modo pelo qual os diversos stakeholders vêem a empresa como uma boa cidadã corporativa (DOWLING, 2002: 53). Nesse contexto, o efetivo comprometimento socioambiental das empresas envolvendo todos os seus stakeholders é uma das principais métricas para construçáo da reputação corporativa das empresas.

Além disso, há uma tendência cada vez maior de empresas e executivos serem responsabilizados administrativa, civil e criminalmente por descumprimento de obrigaçóes ambientais. Para prevenir isso, é necessário um ativo processo de gerenciamento e minimização dos riscos, monitorando integralmente os sistemas de produção para mitigar ao máximo os danos ambientais, com isso, zelar pela saúde dos colaboradores, clientes, visitantes e a comunidade do entorno.

Um exemplo de ameaça à reputação das empresas impulsionando o Direito foram as denúncias de "dumping" sócio ambiental que o setor sucroalcoleiro do Brasil enfrentou. A ameaça da plantação de cana em áreas de florestas, as queimadas e o uso da mão de obra do boia fria em condiçóes degradantes foram as principais justificativas das denúncias.

Em resposta a essas pressóes, antes mesmo de haver processo na $\mathrm{OMC}$, surgiu o Decreto Lei n. ${ }^{\circ} 42.056$ de 06 de agosto de 1997 (D.O.E. 07/08/1997) que fixou prazo para adoção de medidas para erradicação da queima da cana, foram feitos muitos estudos e métricas de acompanhamento para comprovar que a produção de cana não causava desflorestamento, pelo contrário estava em área já de produção agrícola consolidada e permitia inclusive o manejo e recuperação de solos degradados. 
Assim, por mais que uma condenação efetiva como dumping socioambiental fosse remota, a própria denúncia e ameaça à reputação das empresas sucroalcoleiras já foi suficiente para gerar comprometimento e alteração na conduta, consequentemente favorecendo a atuação mais responsável e inclusiva.

Talvez seja possível o uso da tecnologia de fraturamento hidráulico de forma sustentável. Os estudos técnicos, dentre eles a pesquisa do grupo Tecnologia e Risco, vão apontar se há ou não essa viabilidade e quais devem ser as condicionantes e regulaçóes aplicadas. Mas de qualquer forma, a maneira como tem sido feita a exploração atualmente, sobretudo nos EUA, parece ter acarretado prejuízos ambientais reiterados, o que possibilita a concluir que o baixo custo conseguido para o gás náo convencional explorado sob tais condiçôes predatórias ao meio ambiente é artificial, só é conseguido porque deixa de precificar a gestão ambiental responsável e as eventuais medidas mitigatória dos impactos.

Nessas circunstâncias deveria ser cabível portanto o acionamento do sistema de solução de controvérsias da OMC para coibir essa forma de concorrência desleal que além de distorcer o mercado ainda compromete o meio ambiente sadio que é bem de uso comum do povo, necessário à sadia condição de vida tanto de todos os atuais habitantes do planeta como também das futuras geraçóes.

\section{Conclusões}

A realização da pesquisa descrita neste artigo ainda está em desenvolvimento, será aprofundado o tema no curso do programa de Doutorado em Direito Internacional Ambiental da Universidade Católica de Santos, estão previstas entrevistas com especialistas, análise documental e pesquisa bibliográfica.

Por hora, os estudos apontam para a possibilidade jurídica de ser considerado dumping ambiental a forma com que age a indústria de extração de gás, quando implementa a tecnologia de fraturamento hidráulico, uma vez que há negligência com a preservação do meio ambiente e não é aplicada a legislação ambiental, principalmente a voltada para proteção das águas.

Dessa maneira, os baixos preços do gás de xisto não internalizam os custos ambientais no momento da produção do combustível. Assim, a derrubada do preço desses hidrocarbonetos não convencionais é artificial e lesiva à livre concorrência em termos de comércio internacional e portanto distorce o mercado, dificultando ainda mais a competitividade das fontes renováveis de energia e afastando a viabilidade econômica de diversos projetos mais sustentáveis.

Em razão disso, medidas restritivas ao comércio, como subsídios não acionáveis para fomentar energias renováveis poderiam ser aplicadas, caberia, também, acionar os 
mecanismos previstos nos Acordos Preferenciais de Comércio exigindo padróes regulatórios ambientais e ser considerado "dumping ambiental".

Assim, a prática poderia ser denunciada perante a OMC para que o Sistema de Solução de Controvérsias autorizasse a imposição de medidas compensatórias que pudessem ser aplicadas pelos países a todos os produtos que tivessem como insumo a energia proveniente do gás de xisto e que dessa forma se beneficiaram do baixo preço conseguido via dumping ambiental.

Mesmo que não fossem efetivadas essas medidas compensatórias, o próprio constrangimento internacional em virtude de o país figurar como réu em um processo desse tipo parece que já seria suficiente para motivar maior comprometimento dos países com as normas ambientais próprias e também com os compromissos internacionais.

\section{Referências}

AMARAL JÚNIOR, Alberto do. Comércio internacional e a proteção do meio ambiente. São Paulo: Atlas, 2011.

ARANA, Juan Diego Sández . Fracturación hidráulica y comunidades autónomas: a propósito de dos proposiciones de ley presentadas en Andalucía. AJA - Actualidad Juridica Ambiental, 2015. Disponível em: <http://www.actualidadjuridicaambiental.com/articulo-doctrinal-fracturacion-hidraulica-y-comunidades-autonomas-a-proposito-de-dos-proposiciones-de-ley-presentadas-en-andalucia/>. Último acesso em abril de 2015.

BALDIN, Michelle Ratton Sanchez (org.). Tendências regulatórias nos acordos preferenciais de comércio, IPEA, 2012. Disponível em: <http://www.ipea.gov.br/agencia/images/stories/PDFs/livros/livros/livro_tendencias_regulatorias1.pdf>. Último acesso em abril de 2015.

BARROS, Erica Ludmila Cruz. O dumping ambiental no setor sucroalcooleiro à luz do princípio da livre concorrência. 2010. 112 f. Dissertação (Mestrado em Constituiçáo e Garantias de Direitos) - Universidade Federal do Rio Grande do Norte, Natal, 2010. Disponível em: <http://repositorio.ufrn.br:8080/jspui/handle/123456789/13917>. Acesso em 22 março 2015.

BECK, Ulrich. La sociedad del riesgo: hacia una nueva modernidad. Barcelona, Paidós, 1998

BRADY, William. Hydraulic Fracturing Regulation in the United States: The Laissez-Faire Approach of the Federal Government and Varying State Regulations. University of Denver, Sturm College of Law Grimshaw \& Harring, P.C., 2011. 
Disponível em <http://www.law.du.edu/documents/faculty-highlights/Intersol2012-HydroFracking.pdf >. Acesso em 22 março 2015.

BRASIL. Constituição Federal de 5 de outubro de 1988. Constituição da República Federativa do Brasil de 1988. Diário Oficial da República Federativa do Brasil, Brasília, DF, 5 de outubro de 1988. Disponível em: <http://www.planalto.gov.br/ ccivil_03/constituicao/constituicaocompilado.htm>. Acesso em 22 março 2015.

BRASIL. Lei no 6.938, de 31 de agosto de 1981. Dispóe sobre a Política Nacional do Meio Ambiente, seus fins e mecanismos de formulação e aplicaçáo, e dá outras providências. Diário Oficial da República Federativa do Brasil, Brasília, DF, 31 de agosto de 1981. Disponível em: <http://www.planalto.gov.br/ccivil_03/leis/16938. htm>. Acesso em 22 março 2015.

CHPNY, Concerned Health Professionals of New York. Compendium of scientific, medical, and media findings demonstrating risks and harms of fracking (unconventional gas and oil extraction) December 11, 2014, Disponível em: < http:// concernedhealthny.org/wp-content/uploads/2014/07/CHPNY-Fracking-Compendium.pdf > . Último acesso em abril de 2015.

CRUZ, Cássia Vanessa Olak Alves. Reputação corporativa e nível de disclosure das empresas de capital aberto no Brasil. Revista Universo Contábil, FURB, Blumenau, v. 6, n.1, p. 85-101, jan./mar., 2010. Disponível em:< www.furb.br/universocontabil > Acesso em 22 março 2015.

DENNY, Danielle Mendes Thame. Gás de xisto ameaça renováveis. Fonte de energia do momento derruba o preço do 'velho carbono', afirmam especialistas. Revista Ambiente Legal, AICA, São Paulo, 2013. Disponível em: < http://www.ambientelegal. com.br/gas-de-xisto-ameaca-renovaveis/ > Último acesso em fevereiro de 2015.

DENNY, Ercílio A. A verdade como liberdade. Piracicaba, Edicamp , 2004.

DENNY, Ercílio A. e DENNY, Danielle M. T. Hermenêutica e argumentaçáo. Editora Edicamp. Piracicaba. 2005.

DENNY, Ercílio A. Ética e Política I. e II 2. ed. Capivari: Opinião E., 2001.

DENNY, Ercílio A. Interpretar e Agir. Capivari: Editora Opinião E., 2002.

DENNY, Ercílio A. Liberdade e responsabilidade. Piracicaba, Editora Opiniâo E, 2004.

DENNY, Ercílio A. Política e Estado. Capivari: Editora Opinião E., 2000.

DUAILIBE, Allan Kardec (Org.). Combustíveis no Brasil. Rio de Janeiro: Synergia: Centro de Estudos de Energia e Desenvolvimento, 2012.

EIA, Energy Information Administration. Shale gas and tight oil are commercially produced in just four countries. February 13, 2015 Disponível em: < http://www.eia. gov/todayinenergy/detail.cfm?id=19991>. Último acesso em abril de 2015. 
EIA, Energy Information Administration. Shale gas provides largest share of U.S. natural gas production in 2013. November 25, 2014 Disponível em: < http://www.eia. gov/todayinenergy/detail.cfm?id=18951>. Último acesso em abril de 2015.

EIA, Energy Information Administration. Shale oil and shale gas resources are globally abundant. June 10, 2013. Disponível em: < http://www.eia.gov/todayinenergy/ detail.cfm?id=11611>. Último acesso em abril de 2015.

EPA, 2014. U.S. Environment Protection Agency (website). Study of the Potential Impacts of Hydraulic Fracturing on Drinking Water Resources: Overview for Roundtable Meetings, November 2012. Disponível em < http://www2.epa.gov/ hfstudy/study-potential-impacts-hydraulic-fracturing-drinking-water-resources-overview-roundtable>. Último acesso em fevereiro de 2015.

ESTY, Daniel C. Greenig the GATT: trade, environment, and the future. Washington, DC: Institute for International Economics, 1994.

EUROPA. Recomendación de la Comisión Europea de 22 de enero de 2014. Principios mínimos para la exploración y producción de hidrocarburos (como el gas de esquisto) utilizando la fracturación hidráulica de alto volumen. (L 39/72 DOUE 8.2.2014) Diario Oficial de la Unión Europea, 22 de janeiro de 2014. Disponível em: <http://eur-lex.europa.eu/LexUriServ/LexUriServ.do?uri=OJ:L:2014:039:0072:0078:ES:PDF>. Acesso em 22 março 2015.

FOX, Josh, E.U.A. Gasland II, Filme. 2010. Disponível em <http: //www youtube. com>. Último acesso em fevereiro de 2015.

FOX, Josh , E.U.A. Gasland, Filme. 2010. Disponível em <http: //www youtube.com>. Último acesso em fevereiro de 2015.

FREIRIA, Rafael Costa. Direito, gestáo e políticas públicas ambientais. São Paulo/SP: Editora Senac, 2011.

GRANZIERA, Maria Luiza Machado. Direito ambiental. 3a ed. São Paulo: Atlas, 2014.

MACHADO, Paulo Affonso Leme. Direito ambiental brasileiro. 19a ed. São Paulo: Malheiros, 2011.

MAY, Stefan. Nuevos riesgos, seguridade y prevención: sobre la transformación del estado moderno y de sus forma de actuación jurídica. In ALONSO, Esteban Pérez et al. Derecho, globalización, riesgo y médio ambiente. Valencia: Tirant lo Blanch, 2012

MME, Ministério de Minas e Energia. Boletim mensal de acompanhamento da indústria de gás natural. Edição 94. Janeiro 2015. Disponível em: <http://www.mme. gov.br/documents/1138769/1732803/Boletim_Gas_Natural_nr_94_jan_15+-+- 
Completo.pdf/5955d68b-bb15-4545-9963-bf2e60d1f444>. Último acesso em maio de 2015.

MOBBS, Paul.. Shale gas and public health - the whitewash exposed. The Ecologist. Retrieved July 3, 2014, Disponível em: < http://www.theecologist.org/News/news_ analysis/2385900/shale_gas_and_public_health_the_whitewash_exposed.html>. Último acesso em abril de 2015.

NDRC/FTA, National Resources Defense Council e FracTracker Alliance. Fracking's Most Wanted: Lifting the Veil on Oil and Gas Company Spills and Violations. April 2015. Disponível em: <http://www.nrdc.org/land/drilling/files/fracking-company-violations-IP.pdf>. Último acesso em abril de 2015.

PADILHA, Norma Sueli. Fundamentos Constitucionais do Direito Ambiental Brasileiro. São Paulo: Campus/Elsevier, 2010.

REI, Fernando; CIBIM, Juliana. Direito Ambiental. Coleção 10+. São Paulo:Saraiva,2011.

ROBERTS, Peter W.; DOWLING, Grahame R. Corporate reputation and sustained superior financial performance. Strategic Management Journal, v. 23, n. 12, p. 1077-1093, dec. 2002.

SANBERG, Eduardo Aspectos ambientais e legais do método fraturamento hidráulico no Brasil. Disponível em: < http://www.abes-rs.org.br/qualidade2014/trabalhos/ id903.pdf>. Último acesso em fevereiro de 2015.

THORSTENSEN, Vera (Org.) A regulação do comércio internacional de energia. São Paulo: FIESP, 2013. Disponível em: < http://www.fiesp.com.br/indices-pesquisas -e-publicacoes/a-regulacao-do-comercio-internacional-de-energia/>. Último acesso em fevereiro de 2015.

UE, União Européia. Regulamentos, directivas e outros actos legislativos. Disponível em: $<$ http://europa.eu/eu-law/decision-making/legal-acts/index_pt.htm>. Último acesso em maio de 2015.

WTO, Agreement on Implementation of Article VI of the General Agreement on Tariffs and Trade 1994, Anti-Dumping Agreement, Disponível em: < https://www.wto. org/english/res_e/booksp_e/analytic_index_e/anti_dumping_05_e.htm>. Último acesso em abril de 2015. 